Library Hi Tech, ISSN: 0737-8831

Published: 09. Sept. 2014

\title{
Institutional repository as an important part of scholarly communication
}

Teja Koler-Povh, Matjaž Mikoš, Goran Turk

University of Ljubljana, Faculty of Civil and Geodetic Engineering

Article information: 2014, Vol 32, No. 3, pp. 423-434

To cite this document:

Teja Koler-Povh, Matjaž Mikoš, Goran Turk, (2014),"Institutional repository as an important part of scholarly communication", Library Hi Tech, Vol. 32 Iss 3 pp. 423 - 434, Permanent link to this document:

http://dx.doi.org/10.1108/LHT-10-2013-0146

Publisher's link: http://www.emeraldinsight.com/doi/pdfplus/10.1108/LHT-10-2013-0146 


\title{
Institutional Repository as an Important Part of Scholarly Communication
}

\author{
Teja Koler-Povh, Matjaž Mikoš, Goran Turk \\ University of Ljubljana, Faculty of Civil and Geodetic Engineering \\ Jamova cesta 2, SI 1000 Ljubljana, Slovenia
}

\begin{abstract}
Institutional repositories as a form of scholarly communication have been established as a good practice for quite some time. The European Commission (EC) requires archiving of research articles in institutional repositories (IR) in order to grant international project funding (first in August 2008). Therefore, the interest in IRs should increase in Slovenia as well. In 2011, the IR called DRUGG was built at the Faculty of Civil and Geodetic Engineering (UL FGG) of the University of Ljubljana (UL). By the end of 2013 more than 1800 scholarly publications (B.Sc., M.Sc., and Ph.D. theses) and nearly 200 research articles were archived in it. The DRUGG provides open access to scholarly publications and increases the visibility of the Faculty's scientific publications. Building an IR is a complex project, in which the whole institution has to be involved. Library offers all technical support to the authors by archiving publications to the IR. Thus, the importance and the reputation of the library have increased, since it brings a significant added value to the quality of all activities at the faculty. The statistics of the DRUGG visits and downloads confirms its importance in Slovenia and abroad.
\end{abstract}

Key words: institutional repository, open access, digital repository, library, scholarly communication

\section{Introduction}

Scholarly communication is an important part of activities in academic institutions, and scholarly publications have the central role in it (Halliday, 2001). Graham (2000) recognizes scholarly communication as a system with three basic processes: informal networking (nowadays emails, listservs, web archives), initial public dissemination of research (such as conference papers or preprints), and formal publications (such as in prestigious journals); and the Internet is now an overarching element to all three, since it may provide the transport for all of these. The development of institutional repositories (IRs) is intimately tied and interconnected to two other developments - those of digital libraries and the open access movement (Jantz \& Wilson, 2008).

Today open access (OA) has become the usual practice of publishing results of scientific and research work, mainly in natural sciences and medicine (McVeigh, 2004; Suber, 2007). Two basic principles have been established in the world that provide to the public free OA to scientific publications, frequently called gold path and green path of OA. With the gold path of OA the public is given free access to publications at a publisher's web site. With the green path of OA the public has OA to available publications kept in repositories or storages and findable with customary web search engines (Koler-Povh et al, 2011). Harnad et al. (2004) predicted that the green path of OA would prevail, since it did not change the established system of scientific communication; this, however, cannot be claimed for the gold path. For this reason, they appealed to institutions to set up IRs where scientists could store their publications based on prior agreement with the publisher and according to the Creative Commons licenses. Turk (2011) stated that $95 \%$ of publishers allow this, among them internationally 
recognized commercial publishers, such as Elsevier, Springer, Emerald, Blackwell, Oxford University Press and others.

The paper is about the creation of an IR for the University of Ljubljana (Slovenia), using this case study to discuss pros and cons of digital IRs as a form of scholarly communication.

\section{Access to a large number of scientific publications}

Björk et al. (2008) analyzed publications in Web of Science (WOS apps.webofknowledge.com) and Ulrich databases and found out that around 1,350,000 scientific articles were published in 2006, of them $4.6 \%$ with $\mathrm{OA}$ at the Internet pages of journals immediately after their publication, and further $3.5 \%$ after the customary one year embargo. Additional $11.3 \%$ were uploaded to IRs or to Internet pages of individual authors according to the system of green OA. Thus, almost $20 \%$ of all scientific articles from 2006 are already accessible to the users as OA articles. In later research Björk et al. (2010) found out that the gold OA, i.e. access through publisher's Internet pages, is used in medicine and the related sciences, while the green path - repositories is mainly used in natural sciences and engineering, but much less in social sciences.

Many of those who advocate OA emphasize its influence on better visibility of publications and consequently higher citation rate (Harnad \& Brody, 2004; Antelman, 2004; Eysenbach, 2006). The first to make the bold statement of three time's larger citation for OA publications compared to nonopen access publications was Lawrence (2001). Some oppose such statements (Kurtz et al., 2005; Craig et al., 2007; Norris et al., 2008). Okoye \& Ejikeme (2011) stated that many researchers and librarians are neither familiar nor have assimilated the new culture in their scholarly publishing, and have studied 67 academic librarians in South Eastern Nigeria in order to find out to which extent they have appreciated the culture of using OA and IRs in their scholarly publications. Arlitsch \& O'Brien (2012) claim that lack of visibility in Google Scholar (GS) will limit the ability of IRs to play a more significant role in citation rates, thus e.g. affecting university rankings. Important technical aspect when developing IRs is also the interoperability among digital archiving systems, since systems are built at different times (Seadle, 2010) or at different institutions.

In their research Miguel et al. (2011) found out that journals publishing according to the green OA model, allowing the authors self-archiving of publications, achieve on average higher citation rate than those published according to the business model of gold path or those without OA.

Way (2010) studied the domain of libraries and information sciences and the share of OA articles published from this area in 2007 in twenty journals of the WOS collection. Studying the green path he found out that the number of uploads of publications from this scientific discipline to repositories was modest, which is contrary to the mission of a librarian and an IT expert who should act as a role model for other scientific disciplines.

Linde et al. (2011) analyzed the accessibility of refereed conference articles on Web and founded out, that IRs are very important source for their visibility. $17 \%$ of the studied conference papers were uploaded into IRs, next $13 \%$ were archived on the authors' websites or websites of their institutions. The authors highlighted the role of IRs built on higher education institutions.

Notwithstanding the above stated findings, we cannot ignore the fact that the main mission of OA repositories is electronic archiving of publications and preservation of scientific and cultural heritage. 


\section{Repositories}

The first OA repository arXiv (arxiv.org) was built in January 1991 to store the publications from the areas of physics, mathematics, statistics and computer sciences. Among the first OA repositories was also PubMed Central (www.ncbi.nlm.nih.gov/pmc), built in November 2001, which is a repository for international publications from the area of medicine and the related sciences. Repositories can be thematic, such as arXiv and PubMed Central or they can be IRs, i.e. repositories of universities and research institutes.

There are two registers of open access repositories: Directory of Open Access Repositories (OpenDOAR, www.opendoar.org/find.php?rID=2448) and Registry of Open Access Repositories (ROAR, roar.eprints.org/). The EC has announced in August 2008 mandatory storing in OA IRs for publications from projects financed from the funds of Seventh Research Framework Programme (FP7) for some scientific area (including Engineering), and in October 2013 for publications from the Research Framework Programme Horizon 2020 for all the scientific fields (https://www.openaire.eu/en/open-access/open-access-in-h2020). Many academic, scientific and research institutions have already established the compulsory archiving of publications from all projects of publically financed research; beside the EC these are also the European Research Council and many research institutions, such as CERN in Switzerland (for publications from the areas of particle physics) as well as numerous universities, e.g. universities in Hamburg, Bremen, Zürich, Southampton, many US and Australian universities. Registry of Open Access Repository Material Archiving Policies (ROARMAP) lists 85 funder mandates all around the world (in Australia, Austria, Belgium, Canada, Denmark, European Commission and European Research Council, Germany, Hungary, Iceland, Ireland, Italy, Norway, Peru, Singapore, Spain, Sweden, Switzerland, United Kingdom and United States) (https://www.openaire.eu/en/open-access/mandates-a-policies). The positive influence of mandatory storing on the volume of OA publications was also reported by Harnad et al. (2009).

\subsection{Repositories in Slovenia}

The portal Digitalna knjižnica Slovenije - dLib.si, (Digital Library of Slovenia, www.dlib.si/), which is kept by the National University Library in Ljubljana, is a key web medium through which OA to the cultural heritage and current Slovenian knowledge base is provided. It offers free searching of textual, visual and sound resources, so that user can read, watch and listen to the library material. It is a webportal, built from many databases, e.g. The Slovenian bibliography, Old maps of Slovenian territory, Older Slovenian sound recordings, and licensed databases. For the scientific area the portal dLib.si is specifically important as a provider of OA to some early date issues of Slovenian newspapers, journals and monographs with resolved copyrights. By the end of 2013 it also contained about 900 scientific theses, 80 of them are from the UL FGG, and roughly the same number of reports about scientific projects, especially those financed by the Slovenian Research Agency (ARRS). It also includes publications from about 70 Slovenian scientific journals with about 40,000 scientific papers. The number of other articles exceeds 500,000 units which is a respectable number if the number of Slovenian inhabitants (2 millions) is considered.

Slovenian Co-operative Online Information Systems and Services (COBISS.SI) (www.cobiss.si/cobiss eng.html) was built in 1987 in former Yugoslavia and today it represents the main library system in the Balkan region. It is provided in six countries (Slovenia, Serbia, Macedonia, Bosnia and Herzegovina, Montenegro, Bulgaria, and three more countries (Albania, Kosovo, Croatia) which will join the COBISS.net system (http://www.cobiss.net/) soon. Today regional library network 
COBISS.net includes more than 700 libraries from the region of the Western Balkans; more than 400 of them are Slovenian.

COBISS.SI is the compilation of several sub-systems:

- $\quad$ COBIB, the shared bibliographic database, which represents union catalogue, consisted by local bibliographic databases of participating libraries,

- COLIB, the database on participating libraries with their main data and contacts,

- CONOR, the authority database,

- SICRIS, Slovenian Current Research Information System.

Co-operative library catalogue COBIB (cobiss4.izum.si/) has been an important provider of literature, since the librarians started to include links to Internet pages with full texts. However, this is not a repository; it is a bibliographic database which provides abstracts for most documents and links to the full texts, if they exists.

In October 2013 a pilot national portal as a consortium of IRs of four Slovenian public universities (UL, University of Maribor, University of Primorska and University in Nova Gorica) has been launched. It is a result of Slovenian national project, financialy supported by Ministry of education, science and sport. The consortium was built by scientists and experts from University of Maribor, on the conceptual basis of their repository the Digital Library of the University of Maribor - DKUM (Brezovnik \& Ojstersek, 2011).

The IR of the biggest and the oldest Slovenian university RUL (without university library, who builds above mentioned digital library dLib.si) contains at the end of 2013 around 30,000 units, 18,000 are B.Sc. theses (http://repozitorij.uni-lj.si/Statistika.php). The IR DKUM from University of Maribor (16 faculties and the university library) contains 33,000 units, 21,000 from them are B.Sc. theses (http://dkum.ukm.si/Statistika.php). The repositories from other two Slovenian public universities; University of Primorska links 6 faculties and one institute and has 4,000 units, 2,000 are B.Sc. theses (http://www.odun.univerza.si/Statistika.php), University in Nova Gorica links 7 faculties and colleges and has 1,500 units, 500 from them are B.Sc. theses (http://repozitorij.ung.si/Statistika.php).

\subsection{University of Ljubljana and its IR}

On UL the recommendations by the European University Association (EUA) to establish a system of mandatory uploading of scholarly publications in on-line repositories had not expanded as it might have been expected. By the end of 2012 at the UL only three of 26 faculties and academies of UL kept their own on-line repositories in international open-source software ePrints. These are Faculty of Civil and Geodetic Engineering (UL FGG, drugg.fgg.uni-lj.si/), Faculty of Computer and Information Science (UL FRI, eprints.fri.unilj.si/), and Faculty of Education (UL PF, pefprints.pef.uni-lj.si/). These IRs mainly contain scholarly publications, with emphasis on theses. Two more repositories are kept by another two faculties of UL, Faculty of Economics (UL EF) and Faculty of Social Work (UL FSD). Each of them has about 10 year tradition of electronic archiving of scholarly publications. Unfortunately, they are not in the Dublin Core format which allows connectivity of metadata with the above mentioned opensource software. Some other members of the UL have tried to establish portals of scholarly publications. Based on the acquired experiences, most of them wanted that the UL would find an adequate solution.

To support a joint IR of the UL a large step forward was made in 2012 by popularization and public awareness, and then the portal Open access Slovenia has been built (www.openaccess.si/). In October 
2013 the Repository of University of Ljubljana (RUL) was established, as a part of Consortium of four repositories of four public Slovenian universities. The RUL joined several IRs of its individual members into a unified system. It also encourages other faculties to creating conditions for inclusion of their scholarly publications in the RUL.

\section{Repository of the Faculty of Civil and Geodetic Engineering DRUGG}

In the early stages in 1990's, the web appearance of UL FGG was limited to the development of web pages of the faculty, their chairs and institutes. In the academic year 2005/06 first web classrooms on the Moodle platform (moodle.org) was put into use, and the whole faculty went on this platform for web classes in the academic year 2009/10 (for the currents status see: //ucilnica1213.fgg.uni-lj.si/). The upgrading of the web classrooms with the digital IR DRUGG is another step forward to better quality of study and research work at UL FGG.

The transition started in 2005 when the ULFGG's rules regulating the preparation of graduation works were introduced. They prescribed the delivery of scholarly publications in electronic form to the library, including the author's statement allowing the work to be posted in the faculty's IR. At the same time instructions for their layout and referencing were prepared.

\subsection{Building the IR DRUGG for scholarly publications}

Until March 2011 more than one thousand scholarly publications, intended to be part of the DRUGG, were collected from the period of 2005 onwards. In this time period many initiatives and requests came from the professional public to allow open access to scholarly publications. As public institutes, faculties are required to allow the public to access complete texts of scholarly publications and results of research work financed from public funds. We monitored the development and functionalities of existing tools for the construction of repositories and decided to build an IR in cooperation with the Faculty of Computer and Information Sciences of the UL (UL FRI), based on the example of their own IR built in open-source system ePrints. This is one of the leading systems in the world and it allows connectivity with other similar systems.

Within UL FGG the Faculty's Student Office joined the efforts of building the IR, and by establishing a connection between the Student Information System (called VIS) for managing student records and the ePrints system, the data on graduates and the basic bibliographical records of each scholarly publication were made available. In the library each such record was adequately completed with additional bibliographic data, mainly abstract, and attached to it a file in pdf format. Each file was previously adequately edited, any appendices were arranged and a cover page which includes basic bibliographic and information about the student's advisor was added. Thus, the cover pages of all scholarly publications were made uniform. The organization of the project group is presented in Fig. 1. We are currently also establishing connections to the COBISS/OPAC system using the COBISS ID numbers. The Faculty's IT Services were responsible for the technical communication with UL FRI and for the demanding computer support of the project at UL FGG. We started by establishing a virtual environment with a virtual server of the ePrints system. For proper function, this server needs standard open-source components, LAMP (operation system Linux, web server Apache, data base MySQL and program language Perl). The team at UL FRI adapted the ePrints system to the Slovenian environment, as well as to the needs of UL FGG (Koler-Povh et al., 2012). 


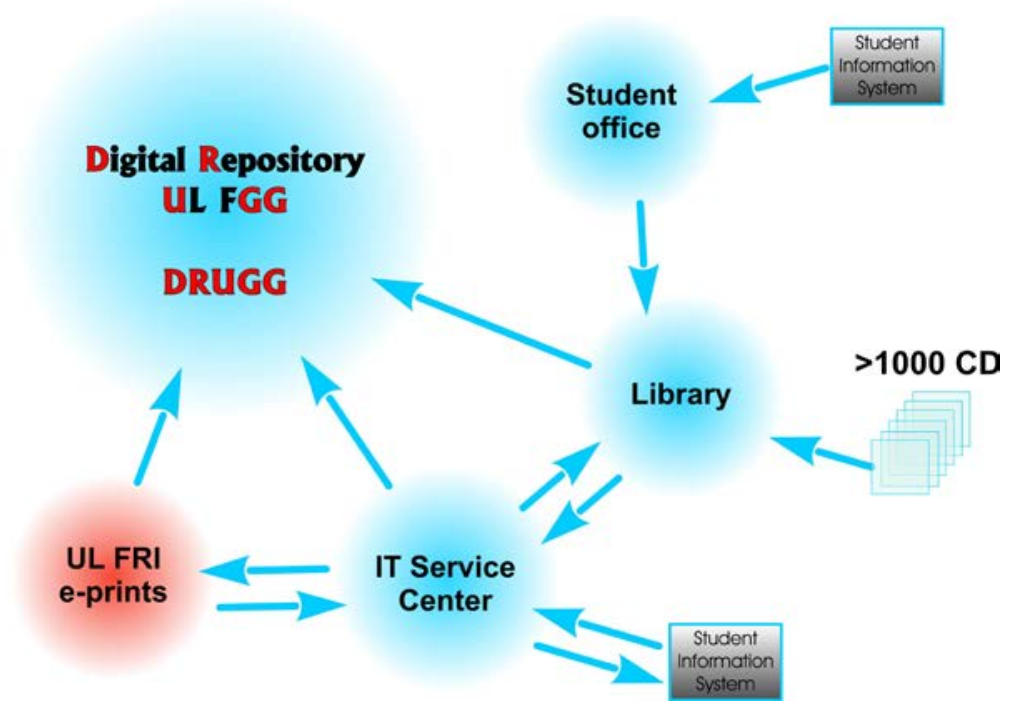

Fig. 1: Organization of the project team at UL FGG for the construction of the IR DRUGG.

The project started in March 2011, and in the time of the Week of UL in December 2011 we delivered the IR to the public. It was called Digital Repository of the UL, Faculty of Civil and Geodetic Engineering, in short DRUGG (drugg.fgg.uni-lj.si/).

\subsection{International registration of the DRUGG repository}

In April 2012 we achieved the international registration of the DRUGG repository in the Directory of Open Access Repositories (OpenDOAR) and in the Registry of Open Access Repositories (ROAR). The DRUGG repository follows the instructions of OpenAIRE, thus meeting the conditions of the EC that publications from projects co-financed from the funds of the EC shall be uploaded in one of the internationally connectible international repositories www.openaire.eu/en/component/ openaire/ingestion2/default/381. It also includes the provision about mandatory delivery of scholarly publications: roarmap.eprints.org/612/. All these are additional reasons that we immediately started to upload also publications by teachers and researchers.

\subsection{Upgrading of the DRUGG repository by bibliographies of the faculty's staff}

The repository also allows uploading and storing of other types of materials, such as articles by teachers and researchers, study materials, multimedia articles, etc. In March 2012 the first scientific articles from journals were uploaded in the repository, and by the end of December 2012 it contained nearly 150 such articles. At the same time, all the employees at the UL FGG were encouraged to deliver to the library the latest reviewed author's version of publications in pdf format, to be uploaded to the repository, after prior checking of the copyright law provisions in the SHERPA/RoMEO list (www.sherpa.ac.uk/romeo/).

When posting scientific papers to the repository it is required by the publisher as well as in the interest of the author that the publication clearly shows where the work was originally published. For this reason the DRUGG editors designed a cover page with a reference formatted according to the rules of the Harvard system of referencing with added Digital Object Identifier (DOI) or electronic address of the publication at the publisher's web page, if DOI does not exist. When storing a large number of publications at the same time, we also use transfer of metadata among different systems, harmonized with the conventional Dublin Core format. We also use DOI identifiers or files formatted in BibTeX, acquired from the WOS system, or COMARC from the COBISS system. 
At the UL FGG we are aware that in order to acquire and upload textbooks we need support of the Faculty's publishing activity. The rules regulating the publishing of textbooks are already planned to be revised. The repository DRUGG can also be used for electronic publishing of textbooks and other teaching materials. Scholarly publications published in DRUGG are planned to be checked in the Turn-it-in system that the UL selected for the plagiarism checking system.

\subsection{Statistics of visits to the DRUGG repository}

Seadle (2011) is convinced, that metrics of repositories migration services is important by judging of its quality. Statistics of visits and downloads is one of important metrics by evaluation of repository's benefits. After two years of operations we are convinced that our decision to build an institutional repository was the right one (namely, the ePrints system allows constant readings of the download statistics). In the first month around four thousand downloads of scholarly publications were observed. In the first year 105.000 downloads of different publications were observed, on the average more than 400 per day, 100 from them from foreign countries. In the second year (2013) the statistics shows 567 downloads per day, $20 \%$ of them are from abroad, most of them from economically developed countries of the Far East, from United States and from the neighboring countries. The download statistics according to contents shows a great degree of topicality of our scholarly publications, as in the first six months of the repository activity many of them had over one hundred downloads each, after two years the most downloaded theses achieve between 1,000 and 3,000 downloads. For instance, in the time of the strong north-eastern wind (known as burja) in Vipavska dolina in February 2012 a thesis on this topic had more than 130 downloads in one week. The thesis entitled "The structural systems of modern wooden roofs” published in the year 2010 is the most downloaded publication of the repository with more than 2800 downloads in two years.

In the first two years DRUGG was used in more than 90 countries on all continents. The geographic areas of visits are shown in Fig. 2. The largest number of visitors comes from Slovenia. Not surprisingly, the response from Europe and America is increasing, but it is surprising that the numbers from countries like United Arab Emirates, Saudi Arabia, Syria, Iran, Iraq, Kazakhstan, Taiwan, Sri Lanka, Indonesia, Malaysia and New Zealand are also increasing. This fact shows the importance of a repository for the promotion of faculty and the UL and its influence on potential new cooperation in science and economy.

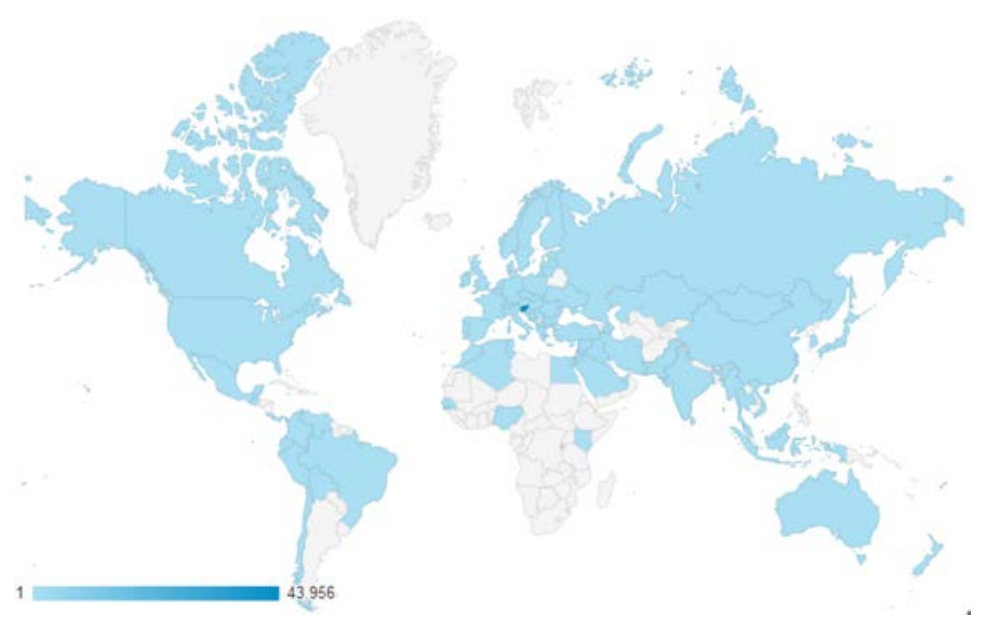

Fig. 2: Geographic areas of downloads from the DRUGG repository in 2013. 
Using Google Analytics also the statistics of accesses from different networks can be monitored. The analysis showed that $89 \%$ of all visits come from public domains, while only $11 \%$ are from the domain of the UL. This proves that the repository is to a large extent used by the professional public and that the use is not limited only to the UL.

\section{The role of library and librarians in building a repository}

The libraries have to adapt to the unavoidable breakthrough of electronic publishing as the consequence of the response of scientists to high prices of scientific publications, mainly periodical, and their simultaneous approval of Internet tools and. The adaption of libraries and their inclusion in the processes of open publishing is expected. Libraries on faculties and higher schools are professional institutions that can and must provide quality support of open electronic publishing. Like Varela-Prado \& Baiget (2012) predicted, the present time librarians should cooperate with other departments and institutions, they should be advising the researchers, creating the bibliographic data, and promoting open access, repositories and open data. Also Asunka et al. (2011) are convinced that the training for users made by library staff is very important for promotion of repositories. On our experiences we can conclude, the librarians should be judged by users on the fact, how expedite they uploaded the documents into repositories, that they are available at the right time.

In the library of UL FGG, the classification of publications according to their contents, introduced in the 1990s, was upgraded in three journals: Gradbeni vestnik (www.zveza-dgits.si/gradbeni-vestnik), Geodetski vestnik (geodetski-vestnik.com/cms/en/), Acta hydrotechnica (ksh.fgg.uni-lj.si/ksh/acta/) by establishing links in the COBISS.SI system to complete texts of articles (early in 2008), offering support in international recognition and visibility of journals, which has always been achieved by the exchange of journals. Further on, since 2005 for the journal Geodetski vestnik continuous archiving of publications in the Directory of Open Access Journals DOAJ (www.doaj.org/) has been arranged. In 2012 we contributed to the visibility of publications of teachers and researchers by archiving the complete texts of their articles and published lectures in the DRUGG repository. The library was one of the most important stakeholders during the process of repository construction and during its use. The librarian supports to researchers by checking OA clauses and by uploading bibliographical units in the repository. By the end of 2013 there were about 200 of them in the repository. For each one of them we first check the publisher approvals according to the SHERPA/RoMEO list of publishers and their contractual copyright conditions for the authors. For the publications in conference proceedings the permissions for electronic archiving are obtained by the authors themselves.

\section{Discussions}

The project of establishing and building an institutional repository at a faculty shall include all expert units that contribute to efficient and rational building of the repository with their knowledge, skills and human resources. Thus, the project of building a repository can become a project of the whole institution, which also assures its survival for the future. By building the DRUGG repository, UL FGG has achieved this goal, since the reliable support by the Faculty's management helped us join the forces of the Student Office, the Library and the IT Services. We are well aware that with the DRUGG repository we have opened new possibilities for better recognition of the Faculty of Civil and Geodetic Engineering and its greater contribution to the globalization of knowledge. In the repository mainly the thesis are archived, which otherwise would not have been published anywhere. They are very interesting for professional engineers working in practice. Unfortunately they are rarely published as an article in the journal.

Another important part of IR are the Ph.D. thesis in the form of monographs. Despite the requirement to publish the original scientific article in international peer reviewed journal from the contents of the Ph.D. theses before the defense of the doctoral theses, publishing of Ph.D. thesis in an IR is very 
important for more detailed presentation of data and results, and especially it is important for the enrichment of professional language and to strengthen national identity. This is very important for small country Slovenia with unique language. The theses were before IR available only in hard copy in the faculty library.

This statement should be a contradiction to one of the observations made by Jantz \& Wilson (2008) in that libraries either do not see a connection between institutional repositories and scholarly communication or, if they do, they are not using the library website to explain and market the benefits of institutional repositories.

The building of institutional repositories by some of the first members of the UL was in May 2012 followed by the decision of the Rectorate of the University to introduce a joint digital repository of the UL, which should increase the visibility of the University in the world, improve the quality of accreditation procedures and improve the University's rank at different world rankings of higher education institutions, especially at the Webometrics - Ranking Web of World Universities (www.webometrics.info). In January 2012 the UL was ranked $1^{\text {st }}$ in the Central and Eastern Europe, $13^{\text {th }}$ in Europe and $80^{\text {th }}$ in the world among 20,372 evaluated higher education institutions from all over the world. In October 2013 such a repository of UL was built. It is a part of Consortium of four repositories from four Slovenian public universities.

\section{Conclusions}

It has become a globally recognized fact that with repositories everyone profits. Authors acquire better visibility of their works, the possibility of higher citation rate, the possibility for their increased scientific impact and the possibility for the protection of copyright on ideas. The users acquire the possibility of immediate access to the results of scientific and research works on the global level. Libraries, especially those at higher education institutions and specialized libraries, with their knowledge and skills can upgrade their role at their institution, while librarians as IT experts and capable experts of communication become an important element in quality education process and in scientific and research work at their institution and in wider environment. Existing international and especially Slovenian repositories, included in the international virtual environment, shall work as an example for establishing and maintenance of repositories, neither only in academic area nor in Slovenia only.

\section{Acknowledgments}

The construction of the DRUGG would've never been completed without a hard work of some devoted individuals: Mojca Lorber (UL FGG, Student office), Andrej Vitek (UL FGG, IT Center), Mira Trebar (UL FRI), Miha Peternel (UL FRI) and Romana Hudin (UL FGG). Their contribution is gratefully acknowledged. The authors would also like to acknowledge the in-depth review of two anonymous reviewers that helped to substantially improve this article.

\section{References}

Antelman, K. (2004). Do open access articles have a greater research impact? College and Research Libraries, 65, 372-382, available at: eprints.rclis.org/archive/00002309/ (accessed on 08/15/2012).

Arlitsch, K. \& O’Brien, P.S. (2012). Invisible institutional repositories - Adressing the low indexing ratios of IRs in Google Scholar. Library Hi Tech, Vol. 30 No. 1, pp. 60-81.

Asunka, S., Chae, H. S., \& Natriello, G. (2011). Towards an understanding of the use of an institutional repository with integrated social networking tools: A case study of PocketKnowledge. Library information science research, Vol. 33 No. 1, pp. 80-88. 
Björk, B. C., Roos, A., \& Lauri, M. (2008). Global annual volume of peer reviewed scholarly articles and the share available via different Open Access options. In Chan, L. \& Mornati, S. (Eds.): Proceedings of the International Conference on Electronic Publishing (ElPub 2008), Open Scholarship: Authority, Community and Sustainability in the Age of Web 2.0, Toronto, available at: oacs.shh.fi/publications/elpub-2008.pdf (accessed on 09/10/2012).

Björk, B. C., Welling, P., Laakso, M., Majlender, P., Hedlund, T., \& Guônason, G. (2010). Open access to the scientific journal literature: Situation 2009. PLoS ONE, Vol 5 No. 6, e11273.

doi:10.1371/journal.pone.0011273, available at:www.ncbi.nlm.nih.gov/pmc/articles/ PMC2890572 (accessed on 09/10/2012).

Brezovnik, J., \& Ojstersek, M. (2011). Advanced features of Digital Library of University of Maribor. International journal of Education and Information Technologies, NAUN, Vol. 5 No. 1, pp. 34-41.

Craig, I. D., Plume, A. M., McVeigh, M. E., Pringle, J., \& Amin, M. (2007). Do Open Access Articles Have Greater Citation Impact? A Critical Review of the Literature. Journal of Informetrics, Vol. 1 No. 3, pp. 239-248, available at: www.publishingresearch.net/Citations-SummaryPaper3_000.pdf. (accessed 09/10/2011).

Eysenbach, G. (2006). The Open Access Advantage. J Med Internet Res., Vol 8 No. 2, e8. www.jmir.org/2006/... (accessed on 08/10/2012).

Graham, T. (2000) Scholarly communication. Serials, Vol. 13 No. 1, pp. 3-11.

Halliday, L.L. (2001). Scholarly communication, scholarly publication and the status of emerging formats. Information Research, Vol. 6 No. 4, available at: http://InformationR.net/ir/paper111.html (accessed 05/01/2014).

Harnad, S., \& Brody, T. (2004a). Comparing the Impact of Open Access (OA) vs. Non-OA Articles in the Same Journals. D-Lib Magazine, Vol. 10 No. 6, pp. 1-6, available at: www.dlib.org/dlib/june04/harnad/06harnad.html (accessed on 08/10/2012).

Harnad, S., Brody, T., Vallieres, F., Carr, L., Hitchcock, S., Gingras, S., Oppenheim, Y., Hajjem, C., \& Hilf, E. (2004). The Access/Impact Problem and the Green and Gold Roads to Open Access. Serials Review, Vol. 30 No. 4, pp. 310-314.

Harnad, S., Carr, L., Swan, A., Sale, A., \& Bosc, H. (2009). Maximizing and Measuring Research Impact - Open-Access Self-Archiving Mandates. Wissenschaftsmanagement Vol. 15 No. 4, pp. 641.

Jantz, R.C. \& Wilson, M.C. (2008). Institutional Repositories: Faculty Deposits, Marketing, and the Reform of Scholarly Communication. The Journal of Academic Librarianship, Vol. 34 No. 3, pp. 186-195.

Koler-Povh, T. (2005). Instructions for layout and referencing in scholarly publications on UL FGG. Ljubljana, University of Ljubljana, Faculty of civil and geodetic engineering, 48 p, (in Slovenian), available at: www.fgg.uni-lj.si/KMTe/documents/academic/navodila-fgg.pdf $\quad$ (accessed on 12/23/2012).

Koler-Povh, T., Južnič, P., Turk, Ž., \& Turk, G. (2011). Analysis of scientific publications in civil and geodetic engineering in Slovenia, in the case of the Faculty of civil and geodetic engineering in University of Ljubljana. Geodetski vestnik, Vol. 53 No. 4, pp. 749-763, (in Slovenian), available at: www.geodetski-vestnik.com/55/4/gv55-4_764-780.pdf (accessed on 12/23/2012).

Koler-Povh, T., Vitek, A., Lorber, M., \& Turk, G. (2012). DRUGG - Digital Repository of UL FGG. Geodetski vestnik, Vol. 56 No. 1, pp. 208-211, (in Slovenian), available at: www.geodetski-vestnik.com/56/1/gv56-1_208-211.pdf (accessed on 12/23/2012).

Kotar, M. (2009). Free-access repository of research and scholarly publications. Knjižničarske novice, Vol. 19 No. 6/7, pp. 8-12. (in Slovenian).

Kurtz, M. J., Eichhorn, G. Accomazzi, A. Grant, C. Demleitner, M. Henneken, E, et al. (2005). The effect of use and access on citations. Information Processing \& Management, Vol. 41, pp. 3951402.

Lawrence, S. (2001). Online or invisible? Nature (London), Vol 411, No. 6837, pp 521. tildalawrence/papers/online-nature01/_may,1,2006 (accessed on 08/28/2012).

Linde, P., Erikson, J.,, Kullman, L., Fathli, M., Karlsson, K., Sikström, M., Sköld, Y., \& Tång, I. (2011). Accessibility and self-archiving of conference articles: A study on a selection of Swedish 
institutional repositories. Information Services \& Use, Vol. 31, pp. 259-269. DOI: 10.3233/ISU2012-0656

McVeigh, M. E. (2004). Open access journals in the ISI citation databases: analysis of impact factors and citation patterns: a citation study from Thomson Scientific, available at: science.thomsonreuters.com/m/pdfs/openaccesscitations2.pdf (accessed on 09/28/2012).

Miguel, S., Chinchilla-Rodriguez, Z., De Moya-Anegón, F. (2011). Open access and Scopus: A new approach to scientific visibility from the standpoint of access. Journal of the American Society for Information Science and Technology, Vol. 62 No. 6, pp. 1130-1145.

Norris, M., Oppenheim, C. \& Rowland, F. (2008). The citation advantage of open-access articles. Journal of the American Society for Information Science and Technology, Vol 59, pp.1963-1972.

Okoye, M.O. \& Ejikeme, A.N. (2011). Open Access, Institutional Repositories, and Scholarly Publishing: The Role of Librarians in South Eastern Nigeria. Library Philosophy and Practice, Paper 612, available at: http://digitalcommons.unl.edu/libphilprac/612 (accessed on 05/01/2014).

Seadle, M. (2010). Archiving in the networked world: interoperability. Library Hi Tech, Vol. 28 No. 2, pp. 189-194.

Seadle, M. (2011). Archiving in the networked world: metrics for testing. Library Hi Tech Vol. 29 No. 3, pp. 557-564.

Suber, P. (2007). Open Access Overview. Focusing on open access to peer-reviewed research articles and their preprints. Last revised June 19, 2007, available at: www.earlham.edu/ peters/fos/overview.htm. (accessed on 09/16/2012).

Turk, N. (2011). Do Open Access Biomedical Journals Benefit Smaller Countries? The Slovenian Experience. Health Information and Libraries Journal, Vol. 28, pp. 143-147.

Varela-Prado, C. \& Baiget, T. (2012). The Future of Academic Libraries: Uncertainties, Opportunities and Challenges. Investigacion Bibliotecologica, Vol. 26 No. 56, pp.115-135.

Way, D. (2010). The open access availability of library and information science literature. College \& research libraries, Vol. 71 No. 4, pp. 302-309.

Webometrics - Ranking Web of World Universities, available at: www.webometrics.info (accessed on 02/05/2013). 